\title{
Shoreline Morphology along Barrier and Mahin Transgressive Mud Coast of Nigeria
}

\author{
Moses Adelakun SALAMI \\ Department of Marine Meteorology and Climate, Nigeria Institute for Oceanography and Marine Research, Lagos, Nigeria.
}

DOI: http://doi.org/10.38177/AJBSR.2020.2405

Copyright: (92020 Moses Adelakun SALAMI. This is an open access article distributed under the terms of the Creative Commons Attribution License, which permits unrestricted use, distribution, and reproduction in any medium, provided the original author and source are credited.

\section{ABSTRACT}

Coastline is one of the most import line features on the surface of the earth. Information about the coastlines morphology is required by the coastal management for proper coastal planning. Over $60 \%$ of the world population lives within few km to the coast. By the turn of the century two-thirds of the population (3.7 billion) in developing countries have occupied the coast. Consequently, unless careful environmental management and planning are instituted, severe conflicts over coastal space and resource utilization are likely, and the degradation of natural resources will close development options. In addition to the population pressure, the world's coastal areas and small islands are highly vulnerable to climate change. Low-lying delta, barrier coasts, low-elevation reef islands, and coral atolls are especially sensitive to the rising sea level, as well as to changes in rainfall, storm frequency, and intensity. The research examined the shoreline changes over time in barrier lagoon coast and mahin mud coast of Nigeria. Satellite images comprising of Landsat MSS, ETM and OLI of 30m by 30m of 1990, 2000, 2010 and 2020; were used as the sources of data. The satellite images underwent series of geo-processing. The bands (red, blue and green) of each image were combined using Arc Map 10.4. The images were added as layer whereby the shoreline from each image was digitized as polylines. The shoreline of 1990 was overlaid on that of 2000, shoreline of 2000 was overlaid on 2010, 2010 on 2020 and that of 1990 on 2020. Thereafter, overlaid maps were converted to polygons using Features to Polygon module of ArcGIS 104. The polygons were grouped to advanced (land gained) or retreat (land lost) with which spatial query was done. The result revealed that Barrier and -mahin mud coast lost about $56.4622 \mathrm{~km} 2$ of land while $4.44275 \mathrm{~km} 2$ was gained between 1990 and 2000 whereas between 2000 and 2010; $6.65259 \mathrm{~km} 2$ was lost while $14.0042 \mathrm{~km} 2$ of land was gained. During the period between 2010 and 2020, the analysis showed that $15.4195 \mathrm{~km} 2$ was gained while $12.2509 \mathrm{~km} 2$ was lost. The percentage change was highest between 1990 and 2000 with $85.41 \%$ of land loss.

Keywords: Barrier lagoon coast, Mahin mud coast, GIS, Landsat, Shoreline morphology.

\section{Introduction}

Coastline is defined as the boundary between land and the water body, is one of the most important linear features on the earth's surface, which has a dynamic nature (Winarso, et al., 2001).Shoreline changes monitoring is an issue of concern in coastal management because of the tendency of the ecosystems to support many population (Moran, 2003) in which the Barrier lagoon coast area is not exceptional. Coastal shorelines worldwide are changing rapidly as a result of natural physical processes and human activities. Natural factors such as sediment supply, wave energy, and sea level rise are the primary causes of coastal changes, whereas human activities are catalysts causing disequilibrium conditions that accelerate changes.

Mentaschi et al., (2006) observed that shoreline changes induced by coastal erosion and accretion are natural processes. However, they have become anomalous and widespread in the coastal zone of African countries owing to series of various natural forces, population growth and unmanaged economic development along the coast, within river catchments and offshore. According to (Khamis et al., 2017), the coastal zone is increasingly under pressure from human activities such as fishing, coral and sand mining, mangrove harvesting, seaweed farming, sewage disposal, urban expansion and tourism. Of particular note is dynamite fishing, over-harvesting of mangroves, coral and sand mining, all of which have profound negative impacts on coastal stability and are thought to lead to coastal erosion and shoreline change. Among other human activities that impact coastline include dredging and physical development, mineral exploration, and construction of ports and removal of vegetation. The 
intensity of coastal erosion has been reported in Tanzania (Makota et al., 2004), Nigeria (Adegoke et al., 2010) and Asian countries like China, Japan, India, Indonesia and Vietnam (Braatz et al., 2006).

The modeling of shoreline changes may be derived from the historical data that include topographical maps, aerial photographs and satellite images. These data can easily be combined and processed with the use of geographical information system (GIS) suggesting that shoreline change is best studied using GIS because of the its ability of combining and comparing satellite images of different time (years) of the same area. GIS is a unique integration or system of computer hardware, software, peripherals, procedural techniques, organizational structure, people and institutions for capturing, manipulating, storing, analyzing, modulating, modeling, and displaying of geographically referenced data for solving complex human-related problems (Eludoyin, et al., 2012). The use of remote sensing and GIS for mapping and analyzing shoreline changes over a period of time has gained prominence in recent years as high resolution satellite data have become more readily available (Adegoke et al., 2010).

Remote Sensing plays an important role in spatial data acquisition from economical perspective (Alesheikh, et al., 2003). Optical images are simple to interpret and easily obtainable. Furthermore, absorption of infrared wavelength region by water and its strong reflectance by vegetation and soil make such images an ideal combination for mapping the spatial distribution of land and water. Therefore, the images containing visible and infrared bands have been widely used for coastline mapping (DeWitt, et al., 2002). Examples of such images are TM (Thematic Mapper) and ETM+ (Enhanced Thematic Mapper) imagery (Chander, et al., 2009). From 1972, the Landsat and other remote sensing satellites have provided digital imagery in infrared spectral bands where the land water interface is well defined. Hence, remote sensing imagery and image processing techniques provide a possible solution to some of the problems of generating and updating the coastline maps (Alesheikh, et al., 2007).

\section{Study Area}

The study area stretches from Badagry from latitude $6^{\circ} 22.540^{\prime} \mathrm{N}$ to $5^{\circ} 51.171 ' \mathrm{~N}$ and longitude $2^{\circ} 42.728^{\prime} \mathrm{E}$ to $5^{\circ}$ 01.178'E (Fig.1), the beach crest elevation of the area is between $3-4$ m above mean sea level. It a tropical maritime area with a coastline of approximately $853 \mathrm{~km}$. The Nigerian coastline stretches from the western border with the Republic of Benin to the eastern border of the Cameroon Republic. The Nigerian coastal zone is defined as the area from the edge of the continental shelf to the inland area covered by swamp forest. Many of Nigeria's population and economic activities are located along the coast, with over $20 \%$ of the population inhabiting the area (Population Reference Bureau, 2001).

The study area cuts across three states (Lagos, Ogun, and Ondo states) of the nine coastal states of Nigeria, which the study area is a subset of. It is about $350 \mathrm{~km}$ long and covers about $6185 \mathrm{~km}^{2}$ of land. The climate is humid tropical with a mean annual rainfall of about $2721 \mathrm{~mm}$. Mean annual number of rain days is about 170, mean monthly rainfall is about $229 \mathrm{~mm}$ and mean annual temperature is about $27.8^{\circ} \mathrm{C}$. Morphologically, the SWCN can be classified into two zones based on districts morphology, ecology, beach type and ecosystem services (Odunuga et al., 2013); these are: - The barrier-lagoon coast complex this extends for $250 \mathrm{~km}$ from the Benin/Nigeria border eastwards to the western limit of the transgressive mud beach; - The Mahin transgressive mud coast and beach this 
extends for $75 \mathrm{~km}$, terminating at the Benin River mouth on the northwest flank of the Niger delta; The study area, which supports delicate ecosystems and a large and increasing human population is also susceptible to human-induced environmental decline (Population Reference Bureau, 2001).

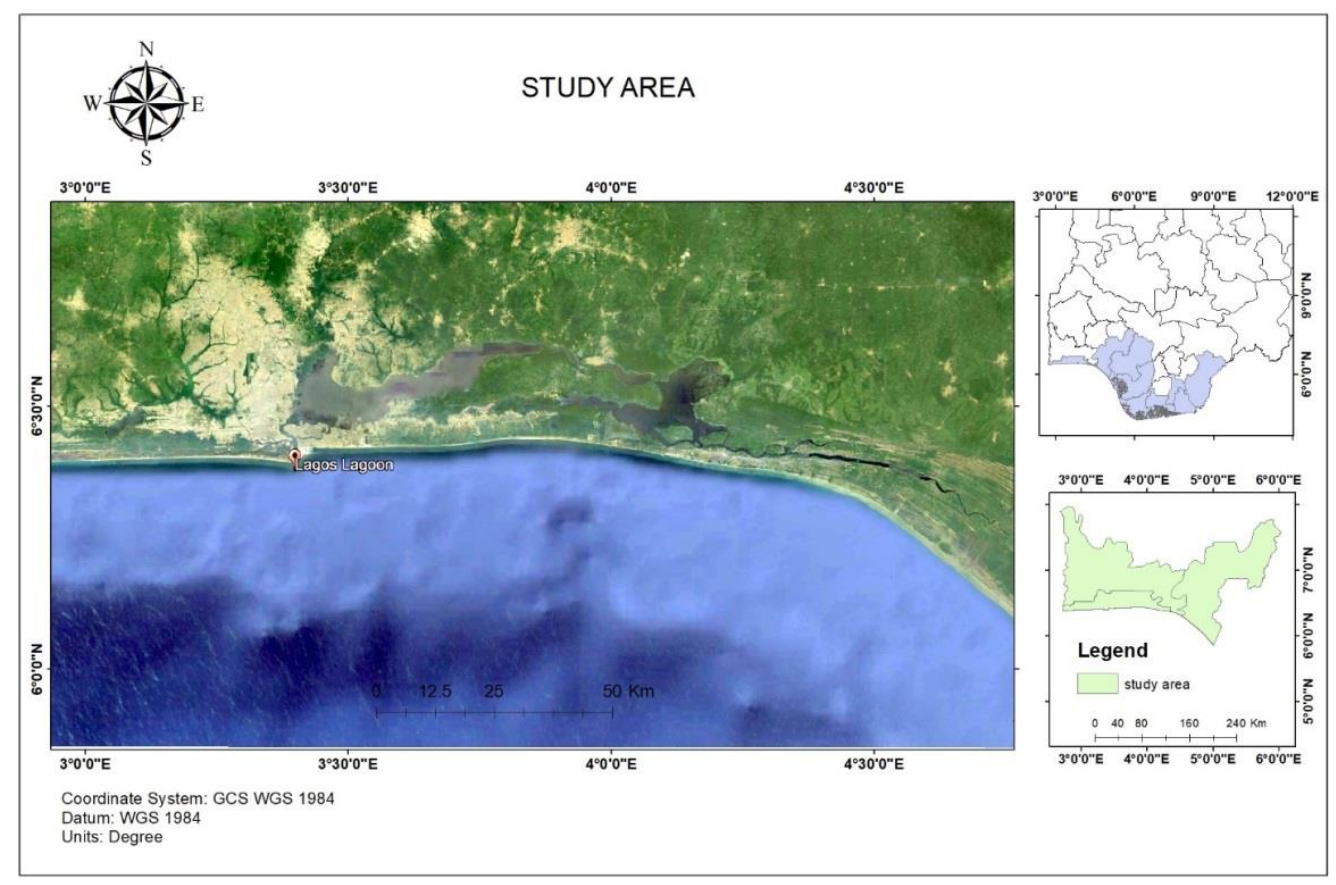

Figure 1: Coastal stretch of Barrie coast and Mahin Mud coast

\section{Methods}

This study made use of satellite images of the study area. Landsat TM, ETM, OLI 30m by 30m of 1990, 2000, 2010 and 2020. The satellite images underwent series of geo-processing in order to make them suitable for further analysis. The bands (red, blue and green) of each image were combined. The color composite facilitates the interpretation of multichannel image data by human eye. Various methods for coastline extraction from optical imagery have been developed. Experience has shown that of the six reflective TM bands, mid infrared band 5 is the best for extracting the land-water interface (Alesheikh, et al., 2007). Band 5 exhibits a strong contrast between land and water features due to the high degree of absorption of mid-infrared energy by water (even turbid water) and strong reflectance of mid infrared by vegetation and natural features in this range. Of the three TM infrared bands, band 5 consistently comprises the best spectral balance of land to water. The modified normalized water index was used along with the color composite 564 and 453 for OLI and ETM respectively. This made it possible to obtain a sharp boundary between the land and ocean which served as the shoreline. Thereafter, the digitization of the shorelines in the images of each year was done in ArcGIS 9.3 as POLYLINES (Vector Data). The digitized shorelines of each year were subjected to spatial analyses. The shoreline of 1990 was overlaid on that of 2000, shoreline of 2000 was overlaid on 2010, and that of 2010 on 2020. This is called overlay analysis. Thereafter, overlaid maps were converted to polygons using FEATURES TO POLYGON module of ArcGIS 10.4. The result of the map then revealed those areas that were advanced or gained into the sea and retreated or lost to the sea. However, the area in square kilometers of either advanced or retreat of overlaid map was calculated and inputted into the relational database. The database was then queried using 
QUERY BUILDER (SQL) of ArcGIS 10.4 in order to group the polygons into advanced and retreat and the total sum of the area in square kilometers of the advanced (gain) and retreat (loss) were determined. Thereafter the percentage gain or loss of land was calculated for the overlaid maps (1990 and 2000; 2000 and 2010; 2010 and 2020). The results of the analysis were presented in tables and maps.

\section{Results and Discussions}

The shoreline captured as line feature from satellite imageries were subjected to geographic analysis. The shorelines of 1990 and 2000; 2000 and 2010; 2010 and 2020 were overlaid.

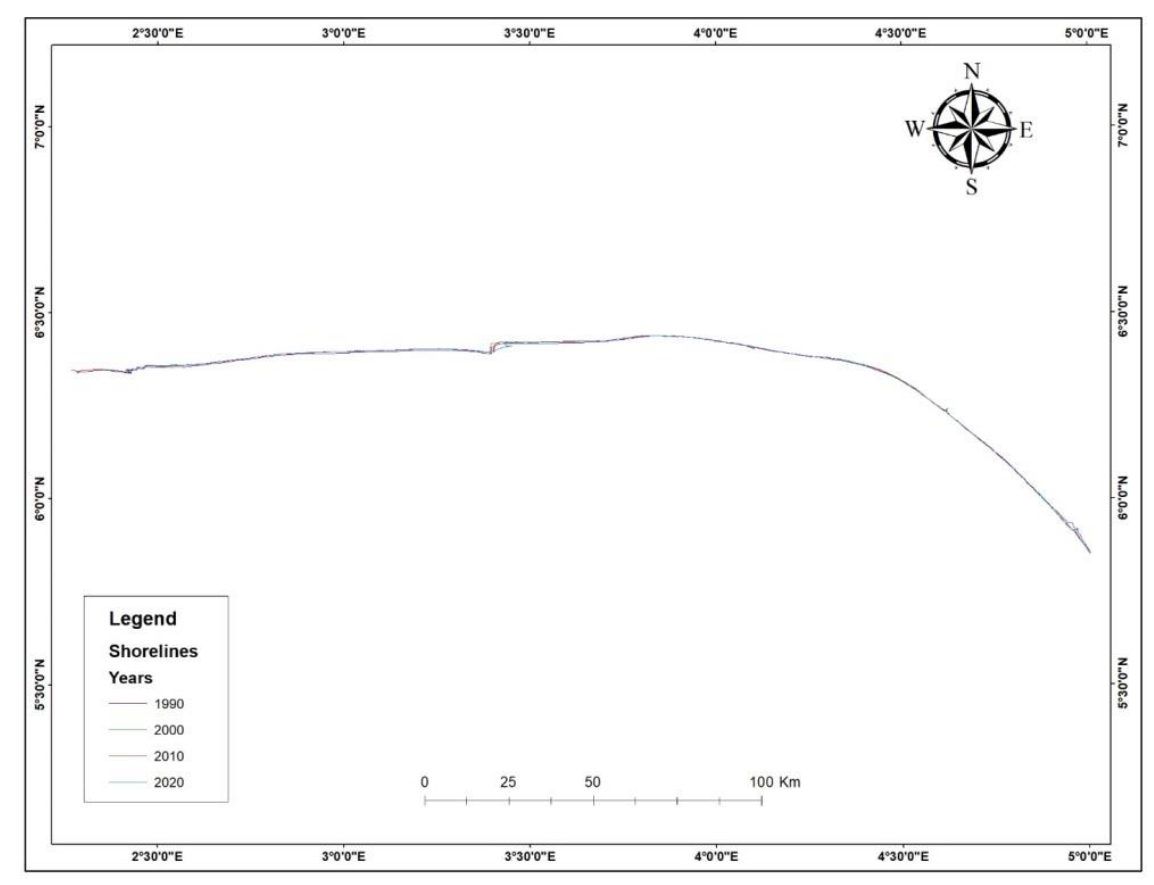

Figure 2: Map showing shorelines of all years in consideration

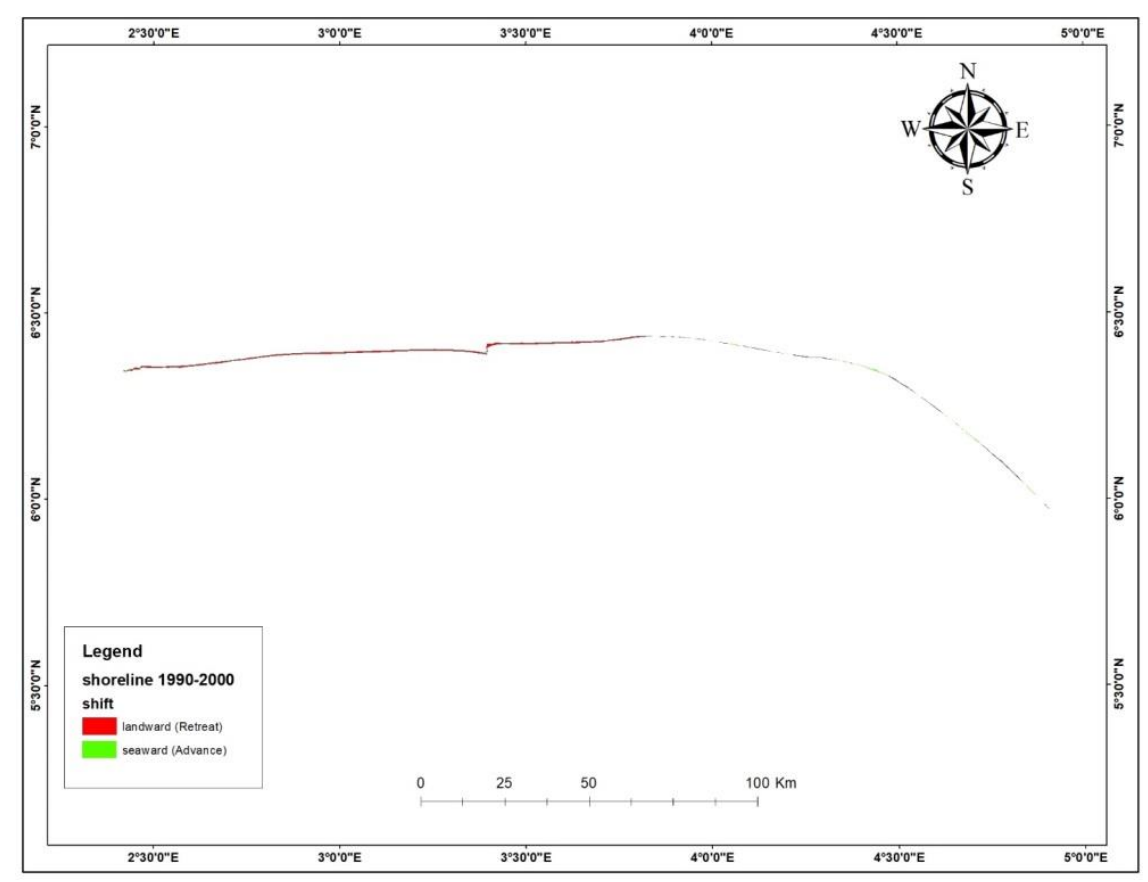

Figure 3: Shoreline changes between 1990 and 2000 
With this analysis, the path at which each shoreline passes gives a quick assessment of the advancement of land into water or retreated of water into the land. The two lines were converted to polygon using feature to polygon module (Figs.3, 4 and 5).

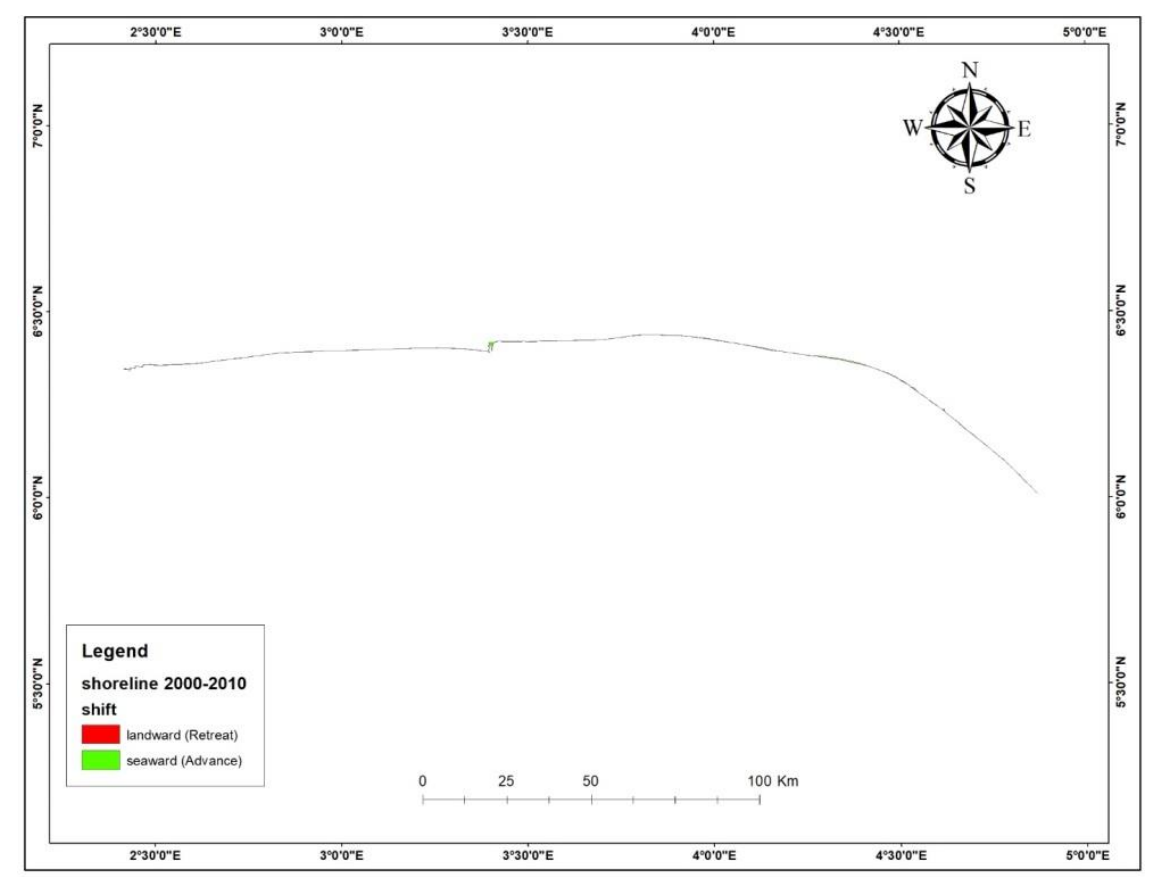

Figure 4: Shoreline changes between 2000 and 2010

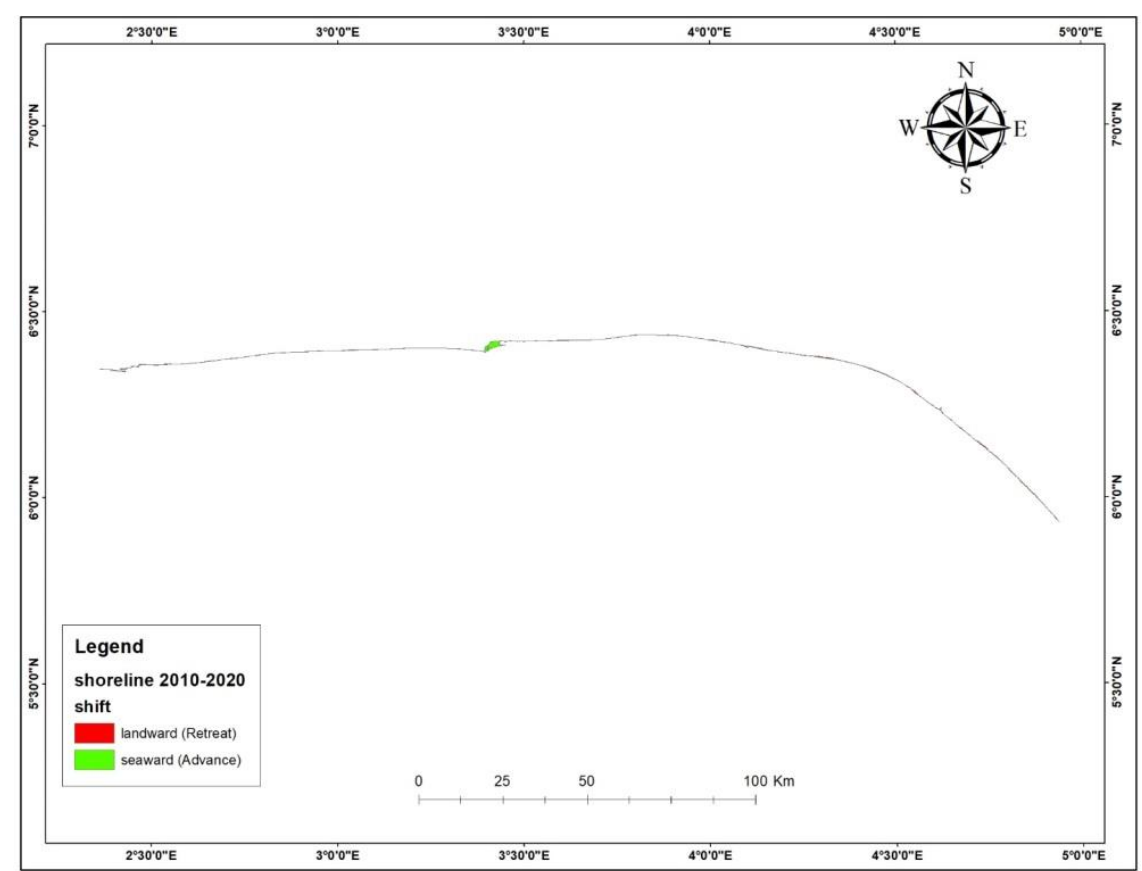

Figure 5: Shoreline changes between 2010 and 2020

These polygons were formed at interceptions in the advanced land into the ocean and retreat into the land. The area of each polygon either advanced or retreat was calculated in square kilometer in each period under consideration. SPATIAL QUERY analysis was also carried out whereby the polygons belonging to either advanced or retreat 
were selected and grouped together and their area in square kilometers were summed together for each period (Table 1).

Table 1: Spatio-Temporal Analysis of Shoreline Changes

\begin{tabular}{|c|c|c|c|c|c|}
\hline Period & Advanced (Gain) (Sq km) & $\begin{array}{c}\text { Retreat } \\
(\mathbf{L o s s})(\mathbf{S q} \\
\mathbf{K m})\end{array}$ & $\begin{array}{c}\text { Total } \\
(\mathbf{S q} \mathbf{K m})\end{array}$ & $\begin{array}{c}\text { Shoreline } \\
\text { Difference (Sq } \\
\mathbf{K m})\end{array}$ & $\begin{array}{c}\text { Percentage Loss } \\
\text { or Gain }(\%)\end{array}$ \\
\hline $1990-2000$ & 4.44275 & 56.4622 & 60.90495 & -52.01945 & -85.41 \\
\hline $2000-2010$ & 14.0042 & 6.65259 & 20.65679 & 7.35161 & 35.6 \\
\hline $2010-2020$ & 15.4195 & 12.2509 & 27.670401 & 3.1686 & 11.45 \\
\hline
\end{tabular}

This is done for the four periods under consideration and thus it is possible to monitor the changes that occurred between these periods and thus the rate of percentage loss and gain was calculated for the periods. Table 1 above shows shoreline changes and rate of change for each period.

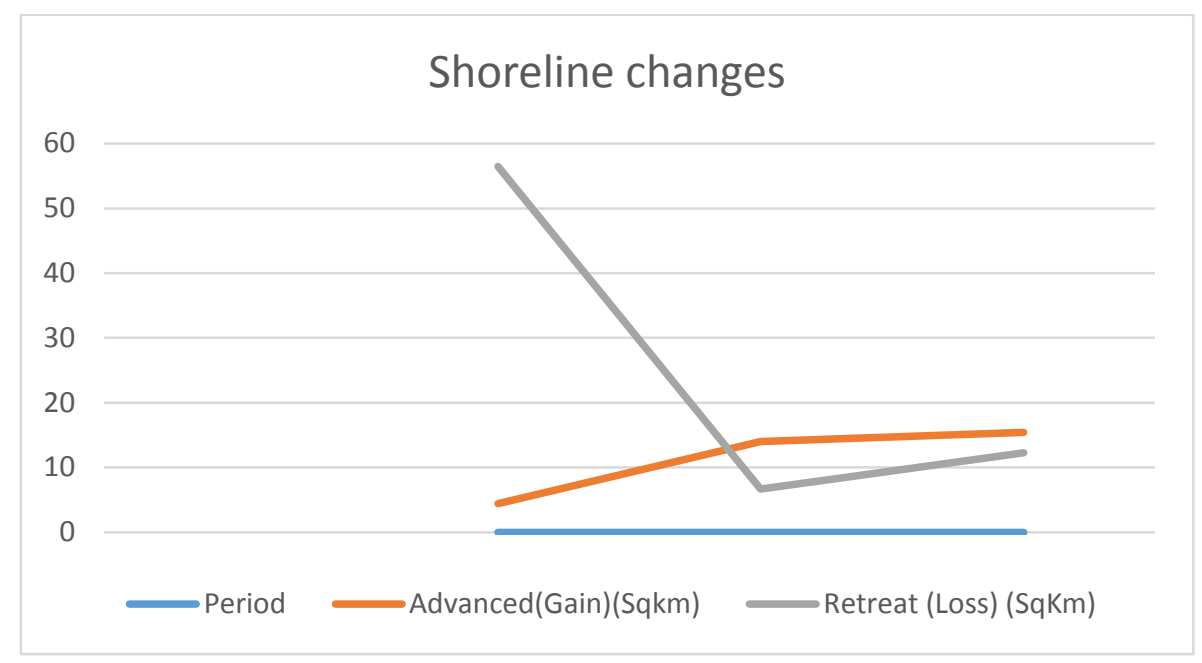

Figure 6: Show shoreline Advanced and Retreat

During the period between 1990 and 2000 the shoreline shifted seaward (advanced) with $4.44275 \mathrm{~km}^{2}$ while the shoreline shifted landward (retreated) with about $56.4622 \mathrm{~km}^{2}$. As a result, $85.4 \%$ of land was lost. During the period between 2000 and 2010 the shoreline shifted seaward with $14.0042 \mathrm{~km}^{2}$ while the shoreline shifted landward with about $6.65259 \mathrm{~km} 2$, thus $35.6 \%$ of land was gained. Between 2010 and 2020, the shoreline shifted landward with $12.2509 \mathrm{~km}^{2}$ while $15.4195 \mathrm{~km}^{2}$ shifted seaward. Assessing the shoreline situation in the periods of consideration, it was observed that much landmass was lost within periods of 1990-2000 while landmass was gained between 2000-2010 and 2010-2020.

\section{Conclusion}

Geospatial approach has been used to study the morphology of the Barrier and Mahin transgressive mud coast of Nigeria. The analysis revealed that the area under investigation has been subjected to both natural and anthropogenic activities such as destruction of coastline by dredging, sand filling and dams of rivers. The impact of 
the intensity of wave also affects the sedimentation level along the coastline. Consequently, the study recommends that dredging in the region should be prevented, mangrove vegetation should be restored and preserved, The combined coastal and marine processes should be controlled, ecosystem conservation and public enlightenment initiatives should be coordinated on a regular basis for people leaving along the coastline to be aware of the vulnerability of the area to storm surge and the adaptation steps that should be put in place.

\section{References}

Adegoke, J.O., Fagbeja, M., James, G., Agbaje, G. and Ologunorisa, T.E. (2010), An Assessment of Recent Changes in the Niger Delta Coastline Using Satellite Imagery Journal of Sustainable Development, 3(4), 277296.

Braatz S., Fortuna S, Broadhead J, and Leslie R. (2006), Coastal protection in the aftermath of the Indian Ocean Tsunami: What role for forests and trees? Proceedings of the Regional Technical Workshop, Khao Lak, Thailand, 28- 31 August

Alesheikh, A. A., Ghorbanali, A., \& Nouri, N. (2007). Coastline change detection using remote sensing. International Journal of Environmental Science \& Technology, 4(1), 61-66.

Ali K.N, Ali A.A, Mohsen S., Mir M.K.(2013), Shoreline Change Mapping Using Remote Sensing and GIS Case Study: Bushehr Province

Chander, G., Markham, B. L., \& Helder, D. L. (2009). Summary of current radiometric calibration coefficients for Landsat MSS, TM, ETM+, and EO-1 ALI sensors. Remote sensing of environment, 113(5), 893-903.

DeWitt H., JR. Weiwen Feng, "Semi-Automated Construction of the Louisiana Coastline Digital Land-Water Boundary Using Landsat TM Imagery"

Eludoyin, O. S., Utang, P. B., \& Obafemi, A. A. (2012). Geographical Information Systems, Urban Forestry and Climate Change: A Review. Research Journal of Environmental and Earth Sciences, 4(6), 640-645.

Khamis, Z. A., Kalliola, R., \& Käyhkö, N. (2017). Geographical characterization of the Zanzibar coastal zone and its management perspectives. Ocean \& Coastal Management, 149, 116-134.

Moran, C.A.A. (2003), Spatio-temporal analysis of Texas shoreline changes using GIS Technique. An unpublished M.Sc thesis submitted to the Office of Graduate Studies, Texas A \& M University. 117p.

Makota,V., Sallema, R. and Mahika, C. (2004), Monitoring Shoreline Change using Remote Sensing and GIS: A Case Study of Kunduchi Area, Tanzania Western Indian Ocean J. Mar. Sci.,3(1), 1-10.

Mentaschi, L., Vousdoukas, M. I., Pekel, J. F., Voukouvalas, E., \& Feyen, L. (2018). Global long-term observations of coastal erosion and accretion. Scientific reports, 8(1), 1-11.

Odunuga, S., Ajijola, A., \& Patience, A. (2013). Geomorphic mapping and human activities along the southwestern Nigeria coastline

Winarso G., (2001). The potential application remote sensing data for coastal study. Singapore. 22nd Asian Conference on Remote Sensing. Singapore. Refer from: http:// gisdevelopment.net/aars/acrs 